\title{
La correspondencia crítica de la enfermedad mortal con el suicidio en el pensamiento de Kierkegaard
}

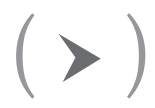

Magdiel Martínez Gómez

Pontifícia Universidade Católica do Rio Grande do Sul, Brasil 


\title{
La correspondencia crítica de la enfermedad mortal con el suicidio en el pensamiento de Kierkegaard"
}

Resumen: en un primer momento, el objetivo del artículo es identificar la correspondencia esencial entre el concepto kierkegaardiano de enfermedad mortal con un concepto general de suicidio, que revele especialmente el interés del autor danés por reflexionar la experiencia de la auto-destrucción. En segunda y última instancia, se busca explicar que la crítica del concepto de enfermedad mortal al suicidio, según Kierkegaard, no se concentra en catalogar como débil la evasión del sufrimiento humano, tampoco parte de escatologías experimentales posteriores a la muerte del cuerpo; en realidad, la crítica se desarrolla a partir del problema que supone una "decisión personal" y de una polémica propuesta sobre "auténtico suicidio".

Palabras clave: Kierkegaard, suicidio, la enfermedad mortal, decisión personal, auténtico suicidio.

\section{Critical connection of the sickness unto death and the suicide in the thought of Kierkegaard}

\begin{abstract}
: at first time, the aim of this article is to identify the essential connection between the kierkegaardian concept of sickness unto death and a general concept of suicide, that reveals especially Kierkegaard's interest in reflecting on the experience of self-destruction. As second and last resort, it expects to explain that the criticism of the concept of sickness unto death to said general concept of suicide, according Kierkegaard, doesn't concentrate on cataloging as weak the evasion of human suffering, neither is born of experimental eschatologies after the death of the body; in fact, the critique is developed starting from the problem that supposes a "personal decision" and a polemic proposal about "authentic suicide".
\end{abstract}

Keywords: Kierkegaard, suicide, the sickness unto death, personal decision, authentic suicide.

Fecha de recepción: 12 de diciembre de 2018

Fecha de aceptación: 27 de febrero de 2019

Forma de citar (APA): Martínez-Gómez, M. (2019). La correspondencia crítica de la enfermedad mortal con el suicidio en el pensamiento de Kierkegaard. Revista Filosofía UIS, 18(2), doi: 10.18273/revfil.v18n2-2019003

Forma de citar (Harvard): Martínez-Gómez, M. (2019). La correspondencia crítica de la enfermedad mortal con el suicidio en el pensamiento de Kierkegaard. Revista Filosofía UIS, 18(2), 35-52.

Magdiel Martínez Gómez: colombiano. Filósofo de la Universidad Industrial de Santander. Maestrando en Filosofía de la Pontifícia Universidade Católica do Rio Grande do Sul, Brasil.

Correo electrónico: magdielmartinezg@hotmail.com

ORCID: 0000-0002-0063-4228

*Artículo de reflexión derivado de investigación. 


\section{La correspondencia crítica de la enfermedad mortal con el suicidio en el pensamiento de Kierkegaard}

\section{Introducción}

Escrita por Søren Kierkegaard, en 1849 aparece publicada La enfermedad mortal o de la desesperación y el pecado ${ }^{1}$; una obra que, a juzgar por su título, plantea una serie de dificultades que conviene responder en las primeras páginas de la obra. En primer lugar, si el objeto de estudio se relaciona con el suicidio, el lector encuentra en la obra pocas referencias del asunto a no ser que lo piense replanteado y trasplantado en el concepto de la enfermedad mortal. Esto implica seguir el procedimiento dialéctico y crítico de Kierkegaard cuando menciona: "Aquí diré lo mismo de un modo distinto" (2009b, p. 261) (SV², vol. VII, p. 245/ SKS, vol. 7, p. 235) $)^{2}$.

En segundo lugar, las pocas veces que hace mención del suicidio es posterior al tratamiento esencial del concepto de enfermedad mortal y sin darle una interpretación explícita desde una línea específica de pensamiento. Por tal razón, la lectura hasta el Segundo libro de la Primera parte de La enfermedad mortal, en donde se definen los aspectos esenciales de dicha enfermedad, precisa que el lector referencie un concepto genérico de suicidio para conectarlo con el concepto de enfermedad mortal. En este orden gradual e interpretativo se realiza el análisis.

En tercer lugar, acaece la imprecisión de no saber si los tres conceptos dados: la enfermedad mortal, la desesperación y el pecado, son uno y el mismo o si hay particularidades entre ellos. "¿En qué consiste, entonces, esa «enfermedad mortal» y por qué se puede hablar de «desesperación»?" (Roldán, 2013, p. 45). En cuanto a lo segundo, es posible responder que entre la desesperación y el pecado hay varias diferencias ${ }^{3}$. No obstante, la tesis de este escrito pretende dirigir la mirada

\footnotetext{
${ }^{1}$ De ahora en adelante, el titulo será abreviado en La enfermedad mortal o LEM.

${ }^{2}$ Se sugiere revisar las ediciones críticas en danés de las obras de Søren Kierkegaard según la última edición de sus obras completas: (SV, vol. VII, p. 245) (SKS, 2012, vol. 7, p. 235). Estas referencias se usarán como apoyo a las versiones en español puestas en cada primer paréntesis dentro del texto.

${ }^{3}$ Principalmente, la diferencia magna señala que la desesperación no está en posesión de los conceptos cristianos como sí lo está el pecado. Lo cual exige revisar la diferencia hecha por Kierkegaard entre la cristiandad y un cristianismo especial que implica "[...] una cierta ignorancia socrática respecto de lo cristiano" (2008, p. 129) (SV², vol. XI, p. 236; SKS, vol. 11, p. 211). El cristianismo viene a diferenciarse de una "cristiandad" que olvida la paradoja y la fe predicadas por Cristo.
} 
hacia la unidad que tanto desesperación y pecado mantienen por cuanto integran la reflexión de la enfermedad mortal en su correspondencia crítica con el problema del suicidio.

\section{La correspondencia esencial entre el suicidio y la enfermedad mortal}

Desde el prólogo, La enfermedad mortal (Sygdommen til Døden) no es ajena a la relación determinante del suicidio (Selvmord) con la muerte que lo distingue de cualquier apariencia y superficialidad. En un entorno preparado para ver la muerte en su paso por el sepulcro, la categoría cristiana de lo edificante, de enorme valor para la fundamentación kierkegaardiana del amor, la fe, la verdad, la ética, en suma, de la interioridad, ahora se perfila en exclusiva a tratar con los hombres enfermos de muerte:

Porque según la regla cristiana todo, absolutamente todo, ha de servir para edificación [...] Toda exposición cristiana tiene que guardar cierta semejanza con las explicaciones que el médico da junto al lecho de un enfermo; de suerte que no se necesita ser un experto en la materia para hacerse una idea de las mismas, atendiendo a la circunstancia perentoria en que se dicen (Kierkegaard, 2008, p. 25) (SKS, vol. 11, p. 117).

Con esta semejanza, se pone en perspectiva metafórica que la temática central de LEM será elevar el rango de crisis para lo edificante. Si algo edifica, debe relacionarse con los enfermos $y$, en especial, con aquellos que yacen tumbados porque una exponencial negatividad les consume sus ganas de vivir. No es descansar por una herida, es estar tirado y desgonzado por una enfermedad que extermina las fuerzas vitales. Para la muestra, Lázaro ${ }^{4}$, el hombre que esperaba a Cristo en el lecho de su enfermedad y murió. Así pues, ¿cómo hablar con alguien a quien toda la vida se le escurre?, ¿cómo lograr tener la atención de aquello que se vacía sin dejar nada?, ¿qué hacer cuando lo vivo ya no puede prolongarse ni siquiera en "un menor grado de ser"? Enfermar de muerte es la gran exageración, es el demasiado mucho (quid nimis) que arriesga la salud mínima para iniciar una conversación como cualquier otra cosa en el mundo. "Cuando se enferma el alma queda el vacío, el vacío interior que es imposible llenar y que desvanece poco a poco nuestro ser" (Ordoñez, 2010, p. 191). No obstante, si lo edificante no quiere verse tejiendo en las nubes, la exigencia es total y clara: debe entrar en relación con los hombres que, concluido el tiempo para pensar, viven su mortalidad.

\footnotetext{
4 "Tras decir esto, añadió: «Nuestro amigo Lázaro duerme; pero voy a despertarle». Le dijeron sus discípulos: «Señor, si duerme, ya se curará». Jesús lo había dicho de su muerte, pero ellos creyeron que hablaba del descanso del sueño" (Juan 11: 11-14, 2009).
} 
Establecida la relación, las dificultades ciertamente no se pueden obviar y lo edificante ha de saber cómo interactuar con la enfermedad mortal. A toda costa, se debe esquivar la tentación de hablar como un "experto", al cual, le persigue el infortunio de hablar sobre objetos que avanzan huérfanos de sus palabras y a quien la eternidad se le pierde en teorías por descuidar las miradas humanas que detienen el tiempo. No hay que ser expertos, tampoco ignorantes. Ni lo uno ni lo otro, simplemente una persona que pueda entender la peculiaridad de un enfermo mortal, su circunstancia perentoria.

Esta circunstancia no es otra que la presencia de un enfermo, postrado en un lecho de muerte, cayendo continuamente sobre su mortandad. A este respecto, Kierkegaard enfatiza: "[...] deseo que los lectores caigan en la cuenta de que en todo este libro [...] la desesperación es considerada como una enfermedad, no como una medicina. Porque en realidad la desesperación es algo muy dialéctico" (2008, p. 26) (SV², vol. XI, p. 133; SKS, vol. 11, p. 118). Tan dialéctico y demasiado contradictorio, que si hay medicina para esta enfermedad es en el mismo sentido que hay distancias luz o medidas muy rápidas que acercan, por lo pronto, objetivos inalcanzables para el hombre. Sin pronóstico alentador, la regresión de la enfermedad escasea de probabilidad. Considerados como la enfermedad mortal, la desesperación (Fortvivlelse) y el pecado ${ }^{5}$ (Synd) son la negatividad más acendrada y riesgosa para las actividades humanas en el mundo. "[...] ser un desesperado representa una caída respecto del poder serlo; y tan profunda es la caída, como infinita la ventaja de la posibilidad. Por consiguiente [...] lo más elevado es precisamente no estar desesperado" (2008, p. 35) (SV², vol. $\mathrm{XI}$, p. 145; SKS, vol. 11, p. 131). De esta forma, quien desespera es un hombre caído y sin esperanza. Puesta la cura de su enfermedad en el paso impredecible y exagerado del no-ser al ser, en un pronóstico reservado, basta imaginar el lecho de su desesperación para preferir la posibilidad por encima de la realidad.

Hasta aquí, el intento de pensar un concepto general de suicidio a través de la enfermedad mortal ha sido efectivo. Ambos conceptos consideran su relación con la muerte de forma determinante; sin quedar nada atrás, hay concentración infinita en el hecho de morir.

Pese a lo anterior, para fijar una correspondencia esencial faltaría ese otro elemento descrito en la investigación de García Aguilar: "La OMS advierte que las tasas de suicidio van aumentando y esto ha provocado la clasificación de una forma peculiar de violencia, denominada por la OMS como violencia autoinfligida" (2013, p. 55). Aunque la definición del suicidio como "violencia autoinfligida" resulte un poco ambigua, por cuanto la violencia no solo implica violencia de muerte, ha de aclararse que, en la situación del suicida, todas las formas de

\footnotetext{
"El pecado, pues, es la elevación de la potencia de la desesperación" (Kierkegaard, 2008, p. 103) (SV², vol. XI, p. 213; SKS, vol. 11, p. 191). Por tanto, el pecado es aquello que "los juristas podrían Ilamar o llaman la «desesperación cualificada»" (2008, p. 103) (SV², vol. XI, p. 213; SKS, vol. 11, p. 191).
} 
violencia emprendidas apuntan a devastar la existencia. Esta mortandad, ante todo, es auto-infligida. Con razones para despreciar la vida tal cual se presenta, la decisión anticipa su destrucción y quedan hechizadas las fuerzas del destino. Para el suicida, morir es una urgencia, es la raíz desde la cual se abre paso la conquista de toda célula hasta convertirlo en el "hombre de la muerte". Sin interventores externos y lejos de esperar la muerte que "a todos les llega" sin haberles llegado, el hombre suicida se auto-inflige la muerte como explosión y detonante al mismo tiempo.

Este abismal deseo de morir, de querer la muerte, también se vive al interior de la enfermedad mortal, la cual no es para el hombre "como otra cualquiera de las enfermedades que contrae, o como la misma muerte que es el destino común" (Kierkegaard, 2008, p. 36) (SV², vol. XI, p. 145; SKS, vol. 11, p. 131). En realidad, "[...] la desesperación es precisamente una autodestrucción" (2008, p. 39) (SV², vol. XI, p. 148; SKS, vol. 11, p. 134). En lugar de vivirse como un padecimiento (passio) en donde el médico monitorea el curso de la afectación, la enfermedad mortal constituye para el hombre el gozo de una esperanza que divisa el enigmático horizonte más allá de la vida como el secreto de su corazón, como aquello que merece el sacrificio de sus ideales y acciones. Sin esperar designios divinos, la muerte es para un enfermo mortal la esperanza que justifica la insurrección de los mortales para vivirse como mortales o, si se prefiere, es la ocasión donde "[...] la muerte es esperada con más intensidad" (Ordoñez, 2010, p. 191). En retrospectiva, cuando se habló de aquel hombre yaciente en su lecho de muerte, enfermo hasta más no poder, desprovisto de medicina, se hablaba de alguien enfermo por propia voluntad, de alguien que un día cualquiera alimentó pensamientos mortíferos y estos progresivamente palidecieron su cuerpo, su entorno y sus relaciones con el mundo.

Por tanto, explicada la enfermedad mortal como concentración infinita de su autodestrucción (Selvfortærelse), se ha fijado una correspondencia esencial del suicidio con la enfermedad mortal que evidencia el interés de Kierkegaard por pensar este tipo de experiencia límite de la vida. A pesar de no usar el concepto de suicidio, la investigación de Rafael de Castro y Aline Grunewald destaca el hecho de que otros pensadores clásicos de la historia filosófica, como Albert Camus, encuentren en Kierkegaard un pensador, entre tantas cosas, del suicidio: "Camus dedicou uma fração significativa de O Mito de Sísifo compondo diálogos com Kierkegaard, fazendo-o o exemplo mais toante de suicida filosófico. O filósofo dinamarquês tornara-se exemplar por render-se estupefato —levado por intensa atração— ao fascínio incomensurável do irracional" (2018, p. 230)6 .

\footnotetext{
"Camus dedicó una fracción significativa de El mito de Sísifo a la composición de diálogos con Kierkegaard, haciéndolo el ejemplo más importante de suicida filosófico. El filósofo dinamarqués se torna ejemplar por rendirse estupefacto - llevado por intensa atracción- a la fascinación inconmensurable de lo irracional" (traducción propia).
} 
Ahora bien, es momento de abrir camino hacia la crítica implícita en la correspondencia esencial de la enfermedad mortal con el suicidio. El punto de inflexión comienza en la Introducción de LEM. De antemano, Kierkegaard aclara que la muerte presente en la enfermedad mortal:

[...] mucho menos la alcanza todo eso a lo que suele llamarse sufrimientos terrenos y temporales: necesidad, enfermedad, miseria, apuros, calamidades, penas, dolores del alma, cuidados y aflicción. Y aunque todo ello fuese tan pesado y penoso que los hombres, al menos los que sufren, se vieran obligados a exclamar: «esto es peor que la muerte» [...] sin embargo, nada de esto [...] puede llamarse en el sentido cristiano una enfermedad mortal" (2008, p. 28) (SV², vol. XI, p. 138; SKS, vol. 11, p. 124).

Como se observa, el foco de la crítica se ubica en reflexionar qué tanta mortalidad tiene el predicado de lo "mortal" en la enfermedad; es decir, si en sentido estricto la muerte cumple el objetivo de arrancar el fundamento de su vida lamentable. Desde una perspectiva temporal y mundana, es factible dar muerte a los tormentos catalogados como pasajeros; incluso, cuando las conversaciones humanas revelen que son "peores que la muerte", tales tormentos, si son pasajeros, constituyen el turismo de una vida desgraciada que, pese a todo, se puede clausurar. De esta manera, la enfermedad mortal sería "[...] un mero sufrir, un sufrir bajo las presiones de lo externo, sin que nunca proceda del interior como una verdadera actividad" (2008, p. 74) (SV², vol. XI, p. 183; SKS, vol. 11, p. 165). Concretamente, el problema consiste en delimitar qué tan profundo cala el deseo de suicidio en el ser humano. En cuanto no radique en el hombre, lo externo (Udvorteshedens) se corresponde con el desaparecer temporal; mientras que lo interior (Indvortes), en cuanto devenga con el hombre mismo, se corresponde con un fundamento no fácil de escapar.

Será en el siguiente capítulo donde la enfermedad mortal y el suicidio expondrán el fundamento de sus lamentos para determinar el modo de sus pretensiones mortales. A medida que se explique la razón por la cual la enfermedad mortal nutre la idea de su autodestrucción, se resolverá la cuestión del capítulo 2 y se complementará el esbozo del capítulo 1.

\section{La diferencia entre "sufrir sin querer sufrir" y sufrir con la esperanza del tiempo}

Para la enfermedad mortal, el motivo de su autodestrucción está cifrado en la expresión: "La desesperación es una enfermedad propia del espíritu"7, más específicamente, porque "El hombre es espíritu" (Kierkegaard, 2008, p. 33) (SV², vol. XI, p. 143; SKS, vol. 11, p. 129). Ser espíritu (Aand) guarda estrecha relación

${ }^{7}$ En LEM, así comienza parte del título de la primera parte; libro primero; capítulo I. 
con ser una respiración (Aand-edrættet) y precisamente "[...] con el subsistir de la personalidad sucede [...] que es un continuo flujo de aspiraciones y exhalaciones" (2008, p. 62) (SV², vol. XI, p. 172; SKS, vol. 11, p. 155). En este orden de ideas, sucede que respirar es la condición y la subsistencia del hombre mediante dos movimientos contrarios: un desprendimiento en la exhalación y una repetición en la aspiración. En un primer momento, aspirar denota llenarse de vida, gozar de continuidad y permanecer en sí mismo. En cambio, el segundo momento lo marca la exhalación que, al filo del detalle, consiste en desprenderse y en ir hacia la muerte por asfixia. Sin ser estáticos, estos momentos contradictorios se experimentan en una relación articulada que constituye el proceso y desarrollo del hombre. Exhalar y aspirar, desprenderse y repetirse, porque dadas las condiciones "[...] repetir lo mismo también significa cambiar bajo las condiciones que se han vuelto difíciles" (Kierkegaard, 2009b, p. 286) (SV², vol. VII, p. 271; SKS, vol. 7, p. 259).

Decir que el hombre es espíritu, (Mennesket er Aand) es significar su condición de hombre contradictorio, de hombre sufriente, en cuanto le atañe ser "una síntesis de infinitud y finitud, de lo temporal y lo eterno, de libertad y necesidad" (2008, p. 33) (SV², vol. XI, p. 143; SKS, vol. 11, p. 129), en cuanto le atañe una guerra por la cual "[...] una cosa nunca deja de ser su contraria" (2008, p. 51) (SV², vol. XI, p. 161; SKS, vol. 11, p. 146). El hombre es la síntesis de un cuerpo con potencial para herir la reflexión del alma (finitud) y de un alma necesitada del cuerpo para no morir en la tristeza del recuerdo (infinitud). En tanto síntesis de tiempo y eternidad, el hombre es un fantasma que desaparece al instante y una eternidad afligida que urge del tiempo para cambiar el destino de su historia. Como síntesis individual y general, cada hombre guarda algo privado (libertad) que el pueblo precisa desvelar para conformar los estados y gobiernos (necesidad).

De estas descripciones, lo esencial es entender que el hombre, sin dejar de ser una cosa contraria, es una síntesis, una relación que vive desmembrada entre una guerra de fuerzas opuestas. Al igual que Sócrates, el cual, "[...] no sabía a punto fijo si era un hombre o un monstruo aún más variable que Tifón" (Kierkegaard, 2009a, p. 94) (SKS, vol. IV, p. 37), el espíritu vive al pie de un detonador. Que el hombre tase el ideario máximo de la felicidad en un método tan violento como el "dominio propio" y en un método tan temeroso como el "arte de la prudencia", obedece, más que todo, al reconocimiento de su ser sufriente, al reconocimiento de una angustia (Angst) precavida que, en el cambio estruendoso y desmesurado del ser al no ser, teme arruinar la concepción de su vida bella. "[...] ne quid nimis [nada en demasía]. Esta sentencia es la summa summarum de toda la finita sabiduría mundana" (Kierkegaard, 2009b, p. 406) (SV², vol. VII, p. 393; SKS, vol. 7, p. 368).

Vistas las cosas de este modo, la vida lamentable y sufriente de un hombre se fundamenta en su interior. Por mucho que el sufrimiento humano se quiera esconder, el hombre es espíritu. Sus tentativas abstractas de culpar a "la vida" 
del dolor, como algo externo que no debería afectarle, dejan de tener validez en el momento que la tristeza lo encarna y lo consume. Sin ser extranjero, el sufrimiento se cuela por las raíces que atan la consciencia del hombre con el mundo e inunda cada fibra del tejido humano. Los nervios de la carne y del espíritu no cesan de confirmar que la realidad humana se caracteriza por vivir en piel propia las aflicciones y entrenarse en la búsqueda de la medicina.

Sin embargo, ¿cómo entender que la mayoría del tiempo el hombre sufra sin querer sufrir? Ambas realidades lo único que hacen es agravar la experiencia del sufrimiento. Con lo cual, el hombre amplía su ser-síntesis mediante una relación entro lo interior y lo exterior en la que, pese a no desear sufrir, tiene en sí mismo la posibilidad de construir la realidad de sus tormentos. Lo clave en este punto es entender lo externo como algo interior, como una actividad digna de ser apropiada en cuanto no deja de estar vinculada con el hombre mismo. De esta manera, aunque el sufrimiento se represente externamente, se debe comprender que, "Mientras el hombre desesperaba de algo, lo que propiamente hacía no era otra cosa que desesperar de sí mismo" (Kierkegaard, 2008, p. 39) (SV², vol. XI, p. 148; SKS, vol. 11, p. 134).

Por consiguiente, "El hombre es espíritu. Mas iqué es el espíritu? El espíritu es el yo" (Kierkegaard, 2008, p. 33) (SV², vol. XI, p. 143; SKS, vol. 11, p. 129). En cuanto yo, el hombre es un espíritu crucificado con lo que sufre, apuntalado al dolor, su cuerpo y alma son actividad sufriente. Más que despreciar sufrir y odiar la vida, su desconsuelo se motiva por escuchar las voces que le ordenan despellejarse y quitarse la cabeza una vez el dolor se incrusta como torrente sanguíneo en su yo interior, en ese corazón del cual mana la vida. Ante todo, la enfermedad mortal se produce por estar la propia carne en juego, por cumplirse aquel principio antiguo: "Piel tras piel. El hombre da por su vida todo lo que tiene" (Job 2:4, 2009). Como ejemplo, Kierkegaard explica que un ambicioso de dominio, el cual fracasa para realizar el lema «o César o nada», “[...] no desespera propiamente sobre el particular de no haber llegado a ser César, sino del propio yo que no lo ha llegado a ser. Y este propio yo [...] es ahora para él lo más insoportable de todo" (Kierkegaard, 2008, p. 40) (SV², vol. XI, p. 148; SKS, vol. 11, pp. 134-135). Por consiguiente, el espíritu es el yo (Aand er Selvet) y el yo "[...] es una relación que se relaciona consigo misma" (2008, p. 33) (SV², vol. XI, p. 143; SKS, vol. 11, p. 129) o, dicho de otra manera, el yo es una síntesis contradictoria que se desmiembra (relaciona) consigo misma en la actividad de su propio sufrimiento.

Arraigada la enfermedad mortal en el interior del hombre, los asuntos humanos, según lo intuido, pueden comportar tanta contradicción que "Una tal relación que se relaciona consigo misma — es decir, un yo - tiene que haberse puesto a sí misma, o haber sido puesta por otro" (Kierkegaard, 2008, p. 33) (SV², vol. XI, p. 143; SKS, vol. 11, p. 129). En caso de ponerse a sí misma o mantener 
un sentido absolutamente independiente, lo siguiente para la síntesis del yo sería arrancarse del sufrir mediante un acto personal y libre que partiera de sí mismo. En posesión de la condición, el característico interés del doliente por suprimir sus lamentos bastaría para quitarle de encima su vida tormentosa, de igual modo, como el deseo y la acción rutinaria le harían cambiar de vestimenta.

Sin embargo, el doliente crónico es un pensador y ejecutor de la alternativa del suicidio. Elevado a la conciencia de comprenderse y experimentarse como espíritu, un hombre "[...] pone de manifiesto una vez más que el absolutamente taciturno no tiene otra salida que la del suicidio" (Kierkegaard, 2008, p. 91) (SV², vol. XI, p. 200; SKS, vol. 11, p. 180). Para el doliente, concentrar en la muerte auto-infligida el brillo de su esperanza, significa reconocer ${ }^{8}$ que su existencia tormentosa no se diluye en vida, como si pendiera sobre su cabeza una espada que no está sujetando. En un sentido, significa reconocer que su pena es en vida un suplicio y una esclavitud. Aunque le viniesen a decir que "no todo está perdido", que "hay algo más", muy en el fondo el suicida comprende que el sufrimiento le persigue, que le deviene por fuerza mayor y a lo sumo la sabiduría humana aprenderá a coexistir con el sufrir mas no a erradicar las vidas tormentosas. Sin la libertad que las cosas adquieren cuando la condición reposa en ellas mismas, "[...] el desesperado cabalmente desespera por eso, por no poder destruirse, y esto es lo que en realidad constituye su tormento" (Kierkegaard, 2008, p. 40) (SV², vol. XI, p. 149; SKS, vol. 11, p. 135).

Así que, "Una relación así derivada y puesta es el yo del hombre; una relación que se relaciona consigo misma y que en tanto se relaciona consigo misma, está relacionándose a otro" (Kierkegaard, 2008, pp. 33-34) (SV², vol. XI, p. 144; SKS, vol. 11, p. 130). Con lo cual, el hombre vuelve ${ }^{9}$ a resultar una síntesis externa e interna que agrava la experiencia del sufrimiento. Al sufrir sin querer sufrir, el suicidio revela que el dolor del sufriente reviste la equiparación con una derivación, en la cual, los efectos no lo tienen por causa. Derivado, el hombre se ubica ante una larga cadena que lo sitúa en un pequeño y singular eslabón sometido a una serie de fuerzas provenientes de un enigmático otro o de un afuera que escapa a su control. Incrustado en este sistema de la trascendencia y derivado de un más allá, el hombre no se puede representar la externalidad del sufrimiento como una temporalidad evanescente, pues al ser lo externo un huésped que habita en él, al tener lo foráneo por hogar sus recónditas habitaciones, el sufrimiento humano reside en una "interioridad especial", en una interioridad que configura la historia íntima de su devenir mientras vive transida por una hostilidad existencial. En síntesis:

\footnotetext{
${ }^{8}$ Entre otro significado implícito en la muerte auto-infligida del suicida, el que se menciona ahora es compatible para la fundamentación que la enfermedad mortal hace del sufrimiento humano. Más adelante, se mostrará que el significado restante difiere del punto de vista actual.

${ }^{9}$ Lo único que cambia en este instante es la acentuación dialéctica de lo externo por sobre lo interno.
} 
A esto se debe el que puedan darse dos formas de desesperación propiamente tal. Si el yo del hombre se hubiera puesto a sí mismo no podría hablarse más que de una sola forma: la del no querer uno ser sí mismo, la de querer librarse de sí mismo; pero no podría hablarse de la desesperación que consiste en que uno quiera ser sí mismo (Kierkegaard, 2008, p. 34) (SV², vol. XI, p. 144; SKS, vol. 11, p. 130).

Por tanto, como ya se ha revelado la impotencia del yo para "no querer ser sí mismo" en medio de sus pesares, la única alternativa viable se concentra en la forma de "querer ser sí mismo desesperadamente". Esta segunda forma, "[...] lejos de constituir una peculiar especie de desesperación, representa por el contrario una forma de tal carácter que en definitiva todas las formas de desesperación se resuelven y convergen en ella" (Kierkegaard, 2008, p. 34) (SV², vol. XI, p. 144; SKS, vol. 11, p. 130).

En últimas, para la enfermedad mortal el hombre no puede soslayar el sufrimiento y solo resta ser sí mismo en el odio de sí mismo. Desde este punto de vista, la naturaleza del sufrimiento es tal que no se puede aniquilar, es tan interior y tan esquivamente interior (externa) que revela la existencia de un yo sufriente relacionado en su origen a un Poder que lo fundamenta. Al incidir en su creación, este supremo Poder neutraliza cualquier aspiración del yo emparentada con librarse de sí mismo y no querer "[...] empezar con y mediante el principio, sino en el principio" (Kierkegaard, 2008, p. 93) (SV², vol. XI, p. 203; SKS, vol. 11, p. 182). De manera enfática, escribe Kierkegaard: “[...] a pesar de todos los esfuerzos de la desesperación aquel Poder es el más fuerte y le constriñe a ser el yo que él no quiere ser" (Kierkegaard, 2008, p. 41) (SV², vol. XI, p. 152; SKS, vol. 11, p. 136). Sin lugar a dónde ir, la enfermedad mortal es el suplicio de querer ser sí mismo en el sufrimiento del espíritu. En el peor de los casos, el suplicio de tener que serlo.

Ahora, teniendo in mente esta mortal enfermedad de la desesperación y el pecado, llega el momento de contrastar perspectivas con la idea que, según Kierkegaard, tiene el suicidio acerca del sufrir.

De entrada, Kierkegaard aclara: "[...] no se puede decir que el suicidio fuese una desesperación" (Kierkegaard, 2008, p. 69) (SV², vol. XI, p. 179; SKS, vol. 11, p. 161). La justificación de esta afirmación reside en el acto esencial del suicida; es decir, en su decisión íntima de arrebatarse la vida con la muerte corporal. Hasta cierto grado $^{10}$, esta decisión íntima alberga la consciencia de la desesperación en cuanto enfermedad mortal; pero, luego, "otro" sentido en esta decisión los distancia. La brecha en sí es producida porque "El suicidio aparece como una

\footnotetext{
${ }^{10}$ Hasta cierto grado cuando se escribió: "Para el doliente, concentrar en la muerte auto-infligida el brillo de su esperanza, significa reconocer que su existencia tormentosa no se diluye en vida, como si pendiera sobre su cabeza una espada que no está sujetando".
} 
opción para finalizar con el azaroso sufrimiento interior de la duda en el existir" (Ordoñez, 2010, p. 193), en tanto parece que "Humanly speaking, death is not the greatest evil in life" (Beabout, 1996, p. 83) ${ }^{11}$ y "Coabitar com a ausência de sentido, como com o fantasma do membro amputado, torna natural pesar continuamente o suicídio como saída" (De Castro Lins y Grunewald, 2018, p. $228)^{12}$.

Tomado como recurso de salida, el suicidio es la esperanza de los cansados para terminar el tormento de haber nacido. Un salto hacia el agujero indómito y desconcertante de la muerte corporal para huir del sinsentido existencial, configura el leitmotiv de este momento. Al cifrarse como salida, el suicidio, o piensa que el sufrimiento es una cuestión temporal o, a partir de su acto, quiero volverlo temporal. Cualquiera sea la opción, lo esencial es querer desaparecer de sí mismo mediante un acto que atestigua estar lleno de mucha esperanza y de una "última posibilidad" para creer en algo eterno.

\section{La diferencia entre morir "para la muerte" y morir corporalmente}

Para comenzar, las explicaciones del capítulo anterior permiten dilucidar en qué sentido la desesperación y el pecado son la enfermedad mortal. En tanto hombre carente de esperanza, la historia sufriente de un desesperado le impulsa a devenir el deseo de "no querer ser sí mismo" que nuevamente lo revierte al martirio de "ser sí mismo". Impotente para hacer lo que quiere, un desesperado se enfrenta con el fatalismo de tener que ser el "sí mismo" que no quiere ser. Sin otro deseo que el de morirse, el "[...] desesperado tiene mucha similitud con la de un agonizante que yace en el lecho de muerte, debatiéndose con ella y sin poder morirse" (Kierkegaard, 2008, p. 38) (SV², vol. XI, p. 147; SKS, vol. 11, p. 133); "En esta última acepción es la desesperación la enfermedad mortal" (2008, p. 39) (SV², vol. XI, p. 148; SKS, vol. 11, p. 134).

Por otra parte, al tener conciencia lúcida de estar delante de ese Otro con el cual el yo se relaciona en la relación por ser espíritu, el cristianismo comprende "[...] que todo pecado es cometido delante de Dios o, dicho con mayor exactitud, lo que propiamente hace de una falta humana un pecado es el hecho de que el culpable tenga conciencia de existir delante de Dios" (Kierkegaard, 2008, pp. 107-108) (SV², vol. XI, p. 216; SKS, vol. 11, p. 194). En sentido cristiano, la muerte viene por el pecado ${ }^{13}$ y lo grave de morir es que se peca delante de sí mismo y

\footnotetext{
11 "Humanamente hablando, la muerte no es el mayor mal en la vida" (traducción propia).

12 "Cohabitar con la ausencia de sentido, como si fuera el fantasma del miembro amputado, torna natural sopesar continuamente el suicidio como salida" (traducción propia).

${ }^{13}$ Como se habla en términos kierkegaardianos del cristianismo, el pecado pasa a ser un concepto que no se puede entender más como debilidad, vicios de la carne o alguno que otro mandamiento de la
} 
"delante de un Dios" (delante de un delante) imposible de apuñalar como se apuñala el cuerpo. “[...] el pecado, pues, es la elevación ${ }^{14}$ de la potencia de la desesperación" (Kierkegaard, 2008, p. 103) (SV², vol. XI, p. 213; SKS, vol. 11, p. 191), el otro factor decisivo de la enfermedad mortal.

Identificado el sentido mortal de la desesperación y el pecado, la inquietud del capítulo 1, consistente en determinar con precisión hasta qué punto la muerte de la enfermedad mortal alcanzaba su objetivo, ha cumplido la promesa de arrojar la diferencia sustancial entre dicha enfermedad y el suicidio. El resultado obtenido es un suicidio que busca devorarse a sí mismo con la esperanza intacta de una salida y una enfermedad mortal que tiene a tiro la mortandad de un fuego inextinguible, de una zarza en llamas incapaz de consumirse.

En lo que sigue, los sentidos de muerte puestos en juego a partir de la diferencia consignada entre la enfermedad mortal y el suicidio, comienzan a tener explicación en el capítulo III del libro I de LEM. En esta sección de la obra, Kierkegaard escribe: "Este concepto de «enfermedad mortal» exige que lo precisemos de una manera muy peculiar. Directamente significa una enfermedad cuyo fin o desenlace es la muerte" (2008, p. 38) (SV², vol. XI, p. 147; SKS, vol. 11 , p. 133), y de seguro, "[...] es la muerte el último trance de la enfermedad, mas la muerte misma no es lo último" (2008, p. 38) (SV², vol. XI, p. 147; SKS, vol. 11, p. 133). Dicho esto, cabe pensar que lo esencial en este punto es pasar del habitual sentido de muerte conclusiva a una muerte que no cesa de realizarse como objetivo.

En su devenir, la desesperación traza un recorrido hasta su auto-destrucción. Trazada la línea, su vida consiste a partir de aquí en un ser para la muerte que tiene como fin o desenlace desaparecer en el horizonte último de su libertad ${ }^{15}$. En situación tan suicida, el desesperado anhela que la muerte corporal sea la cortina tras la cual se desvanecen y desaparecen todas las cosas en sus formas conocidas.

\footnotetext{
ley mosaica. En sentido estricto, la definición del pecado debe comenzar a situarse en la definición más completa y algebraica de la desesperación: "Hay pecado cuando delante de Dios, o teniendo la idea de Dios, uno no quiere desesperadamente ser sí mismo, o desesperadamente quiere ser sí mismo" (Kierkegaard, 2008, p. 103) (SV², vol. XI, p. 213; SKS, vol. 11, p. 191). No obstante, este comienzo está sujeto a una elevación. Para mayor amplitud y detalle el lector puede confrontarse con la segunda parte de LEM titulada: "La desesperación es el pecado".

${ }^{14}$ En la desesperación, el hombre solo sabe estar delante de sí mismo y en este peculiar "delante" puede considerarse creador, totalmente libre de la externalidad interna que lo fundamenta en el poder que también lo ha creado. Luego, "delante de sí mismo", el hombre puede intentar no estar delante de lo eterno, sino en torno a lo eterno. Por ende, a diferencia de la desesperación, el pecado es consciente de lo eterno todo el tiempo y en ello radica la elevación. En este punto, no hay forma de esquivar, de andar por las periferias o alrededor de la eternidad, pues, aunque lo olvide, el pecado ya ha conocido que siempre está delante de Dios, de ese Poder que no puede apuñalar como se apuñala el cuerpo.

${ }^{15}$ Cuando se tiene in mente el suicidio, "después de esta elección no hay posibilidad de hacer otra" (Polo, 2006, p. 47).
} 
Sin embargo, tiempo después el desesperado conmociona. Por más que desee arrancarse el yo que le hace sufrir y desee intercambiarlo con el yo de un hombre multimillonario "sin preocupaciones" o intercambiarlo con el yo de una vida apacible "sin responsabilidad", su desgracia consiste en descubrir la infinita imposibilidad para el intercambio y la destrucción mientras sigue siendo el mismo desesperado que es. En este sentido, ejecutar la muerte, consumirse y desbaratarse solo deja tras de sí el cansancio de no poder morirse. Que morir sea la tarea sin conclusión, la finalidad sin final, hace que lo último no sea la muerte, sino el inicio de una nueva y continua desesperación.

En las notas preliminares de la segunda edición actualizada de La enfermedad mortal al castellano, Parcero Oubiña comenta que la obra habla "de aquella enfermedad que no es materialmente mortal (dedelig), pues no acaba en la muerte, sino para la muerte (til Deden), en tanto que espiritualmente conduce en dirección a esta" (como se citó en Kierkegaard, 2008, p. 10). Por cuanto no alcanza la total extinción de la realidad humana, para Parcero Oubiña, la enfermedad mortal queda estacionada en un ser para la muerte (til Deden) que, al ejecutar la muerte sin poder morirse, revela la posibilidad de una muerte espiritual con indicadores serios de inmortalidad o eternidad. Desde su redacción en el original danés, Sygdommen til Døden, la enfermedad mortal transforma la muerte conclusiva del cuerpo (dedelig) en un para o hasta (til Deden) que no avanza más allá de ser el entusiasmo infinito de un objetivo inagotable.

En la misma dirección, los investigadores anglosajones suelen significar la enfermedad mortal con la expresión "The sickness unto death", en donde "unto death" cumple el mismo rol aclaratorio de "til Deden". De este modo, Beabout afirma: "Despair is the sickness unto death [...] is an attempt to do away with oneself. However, since the self has an aspect that is eternal, it can never completely succeed" (1996, p. 98) ${ }^{16}$. Sin siquiera aniquilarse en el lago del olvido, la indestructibilidad del yo apunta a un espíritu revestido de eternidad. Por consiguiente, "The concept of the sickness unto death does not refer to a physical sickness" (1996, p. 97) ${ }^{17}$, sino a una enfermedad devenida de un mundo espiritual que, en su máxima crisis, degenera hasta la muerte sin poder morirse, lo cual, "[...] indirectly attests to the irrevocable eternity of the self" (Podmore, 2011, p. $50)^{18}$. Sin ser diferente, en castellano se emplea la categoría de lo "mortal" para designar proporcionalmente la ambigüedad de la enfermedad para la muerte. De esta manera, de un hombre mortal se dice que su destino consiste en morir sin estar muerto y de una enfermedad cualquiera se dice que es mortal por destruir al

\footnotetext{
16 "La desesperación es la enfermedad hasta la muerte, [...] es un intento de acabar con uno mismo. Sin embargo, dado que el yo tiene un aspecto que es eterno, nunca puede tener éxito por completo" (Traducción propia).

17 "El concepto de la enfermedad para la muerte no se refiere a una enfermedad física" (traducción propia).

18 "[...] atestigua indirectamente la eternidad irrevocable del yo" (traducción propia).
} 
paciente sin consumir el último suspiro. Aunque, en la práctica, el hombre mortal y la susodicha enfermedad pasen de lo mortal a concluir en la muerte, lo cierto es que, hablando con precisión, el concepto de lo "mortal" designa con anterioridad a todas aquellas cosas que, sin acabar en la muerte material, no por ello dejan de ejecutar la muerte en su mortalidad.

\section{La crítica de la enfermedad mortal al suicidio}

En resumen, explicados los dos tópicos diferenciales entre 1) la consciencia de un sufrimiento interminable para la enfermedad mortal y la consciencia de un sufrimiento temporal para el suicidio; 2) seguido del sentido mortal de morir para la muerte de la enfermedad, en contraste con el sentido de muerte corporal para el suicidio; se procederá a recapitular y a condensar la idea capital de la desesperación para estar en condiciones de gestar y entender la crítica de la enfermedad mortal al suicidio.

En tanto ser para la muerte, el desesperado es quien descubre el yo suficiente para relacionarse con una síntesis tan interior, como externamente interior, que le hace sufrir sin querer sufrir. Hasta en las formas inimaginables, el desesperado se compromete con el proyecto de subastar su cuerpo y espíritu para abandonar "el sí mismo" que le cuesta personificar; sin embargo, aunque solamente fuera a intercambiarlo, un Otro incógnito de la existencia, un Poder externo hundido en lo más profundo de su ser, es capaz de neutralizar sus aspiraciones absolutamente humanas y personales. Sufrir sin querer sufrir, estar destinado a no compartir la total configuración de una existencia tormentosa, deja todo a merced de un Poder trascendente que no hace demasiadas concesiones ni se equipara a la muchedumbre cuando intenta suplantar la voz de Dios. Por eso, "La estructura del sí mismo que expone aquí Kierkegaard consta de tres momentos constitutivos: 1) el relacionarse que es, 2) un relacionarse consigo, y 3) este relacionarse consigo es a la vez un relacionarse con un [...] fundamento extrahumano" (Amengual, 2008, p. 342). Dicha extra-humanidad ${ }^{19}$, es la clave kierkegaardiana para afrontar categóricamente la impotencia de un desesperado al momento de morirse. Con el enemigo invisible e inefable, la rebelión desesperada de la muerte anida el fracaso por cuanto vive la realidad de una hostilidad existencial que traspasa los dominios locales y fronterizos.

Por todo esto, la crítica de la enfermedad mortal no se concentra en catalogar como débil la evasión del sufrimiento humano, tampoco parte de escatologías experimentales posteriores a la muerte del cuerpo; en realidad, la raíz del problema tiene que ver con que la muerte del suicida sea una decisión personal o, de otro modo, el problema radica en querer huir del sufrimiento "[...] sin tener

${ }^{19}$ En Kierkegaard, la extra-humanidad del sufrimiento humano se basa en Dios como el supuesto teológico del cristianismo. 
una idea verdadera de que el suicidio es una desesperación" (Kierkegaard, 2008, p. 71) (SV², vol. XI, p. 180; SKS, vol. 11, p. 163).

A este respecto, lo discutible del suicidio es querer fundamentar la huida de sí mismo en la muerte auto-infligida de una decisión personal que ignore o soslaye la extra-humanidad de su yo sufriente. Sin más remedio que proceder a terminar su existencia desde un abstracto punto cero, el suicida actúa como si olvidara que el sufrimiento humano implica situarse «a partir del principio» (med Begyndelsen) y no «en el principio» (i Begyndelsen). En consecuencia, aunque valga para el suicida que "[...] poseer un yo y ser sin yo es la mayor concesión —una concesión infinita-que se le ha hecho al hombre" (Kierkegaard, 2008, p. 42) (SKS, vol. 11, p. 137), aun así, su principio es mucho más temerario por asentarse en un poder extrahumano que seguramente no piensa la muerte del hombre como lo "último". En definitiva, lo discutible del suicidio es confiar en una decisión impotente que solo sirve para demostrar indirectamente "[...] que la desesperación ha puesto fuego a una cosa refractaria al fuego, a algo que no puede ser pasto de las llamas, es decir: al yo" (Kierkegaard, 2008, p. 40) (SV², vol. XI, p. 149; SKS, vol. 11, p. 135), en tanto lo reviste un Poder eterno e inextinguible.

Ahora bien, la crítica también alcanza un aspecto propositivo; a medida que Kierkegaard intenta mostrar una consciencia más intensa del suicidio como desesperación, el pensador danés construye un posible caso de "auténtico suicidio" fundamentado en "[...] esa enfermedad del yo que consiste en estar muriendo eternamente, muriendo y no muriendo, muriendo la muerte" (Kierkegaard, 2008, p. 39) (SV², vol. XI, p. 148; SKS, vol. 11, p. 134). En esta nueva modalidad, el sujeto en cuestión comprenderá que está "[...] infinitamente lejos de llegar a morir - entendiéndolo en el sentido directo- de esta enfermedad, o de que esta enfermedad termine con la muerte corporal" (2008, p. 38) (SV², vol. XI, p. 147; SKS, vol. 11, p. 133). En efecto, el suicida ejecutará su derecho a la muerte, solo que, del cuchillo en el cuerpo, pasará a enterrar su yo en alguna cripta del mundo con la sospecha penetrante de saber el lugar de su entierro para morir a cada instante. "Pues morir significa que todo ha terminado, pero morir la muerte significa que se vive el mismo morir; basta que se viva la muerte un solo momento para que la viva eternamente" (2008, p. 38) (SV², vol. XI, p. 148; SKS, vol. 11, p. 134). En síntesis, "morir la muerte" y "vivir el mismo morir" exigen que el "auténtico suicidio" reanime su muerte en el último trance de la oscuridad para mantener viva la muerte y repetirla por siempre.

En los términos planteados, la ganancia de esta propuesta es no vender con alto precio la expectativa de la muerte física, ahorrarse una desilusión quizás imperdonable. Lo más negativo, "[...] que la desesperación no lo devore por completo; este consuelo es cabalmente su suplicio, y lo que mantiene la carcoma en vida y a la vida en la carcoma" (2008, p. 38) (SV², vol. XI, p. 148; SKS, vol. 11, p. 134). 


\section{Consideraciones finales}

1) Teniendo en cuenta el desarrollo adquirido, se logra identificar que entre la enfermedad mortal y el suicidio hay una correspondencia conceptual que permite hasta cierto grado emplazar los términos sin ningún inconveniente. De hecho, en el punto más álgido de esta relación positiva, la crítica de la enfermedad mortal no sugiere excluir el suicidio, sino proponer un posible "auténtico suicidio".

2) Por otro lado, se pudo determinar que la crítica de la enfermedad mortal al suicidio tiene por objeto de causa el arraigo a una "mala decisión". Ejecutar y mantener la esperanza de la muerte física mediante el uso desmedido de la libertad personal, es el motivo que fractura la correspondencia esencial entre el suicidio y la enfermedad mortal.

\section{Referencias}

Amengual, G. (2008). Experiencia, Verdad y Existencia en Søren Kierkegaard. Revista Portuguesa de Filosofía, 64(2-4), 1037-1055.

Beabout, G. R. (1996). Freedom and Its Misuses: Kierkegaard on Anxiety and Despair. Milwaukee: Marquette University Press.

De Castro Lins, R. y Grunewald, A. (2018). O rosto divino do Absurdo -do suicídio de Kierkegaard. Revista Fronteiraz, (20), 222-239.

García Aguilar, J. F. (2013). Una mirada al dolor: la idea del sufrimiento existencial en el pensamiento de Sören Kierkegaard. Scientia Helmantica, 1(2), 41-63.

Kierkegaard, S. (2008). La enfermedad mortal. (D. Gutiérrez Rivero, trad.). Madrid: Trotta.

Kierkegaard, S. (2009a). La repetición. (D. Gutiérrez Rivero, trad.). Madrid: Alianza Editorial.

Kierkegaard, S. (2009b). Postscriptum no científico y definitivo a migajas filosóficas. (N. Bravo Jordán, trad.). Ciudad de México: Universidad Iberoamericana.

Kierkegaard, S. (1997-2012). Søren Kierkegaard Skrifter. N. J. Cappelorn; J. Garff; J. Knudsen; J. Kondrup y A. McKinnon (eds.). Kobenhavn: Gyldendal.

Kierkegaard, S. (1920-1936). Søren Kierkegaards Samlede Værker. A. B. Drachmann; J. L. Heiberg; H. O. Lange; A. Ibsen y J. Himmelstrup (eds.). Kobenhavn: Gyldendal. 
Nueva Biblia de Jerusalén (2009). Bilbao: Descleé de Brouwer.

Ordóñez, E. J. (2010). La condición humana: de la muerte y el suicidio. Una Lectura de la obra de Albert Camus. Revista Científica Guillermo de Ockham, 8(1)183-195.

Podmore, S. D. (2011). To Die and Yet Not Die: Kierkegaard's Theophany of Death. En P. Stokes y A. J. Buben (eds.), Kierkegaard and Death (pp. 45-64). Bloomington: Indiana University Press.

Roldán, A. (2013). La influencia de Sören Kierkegaard en la teología de Karl Barth: Dialéctica, desesperación y fe. Teología y cultura, 10(15), 40-56. 